\title{
Increased risk of esophageal perforation in eosinophilic esophagitis
}

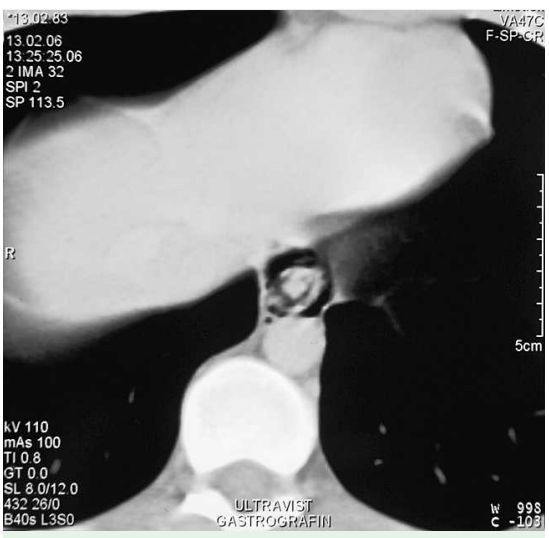

Fig. 1 Computed tomography thoracic scan: periesophageal gas collection, indicative of esophageal perforation.

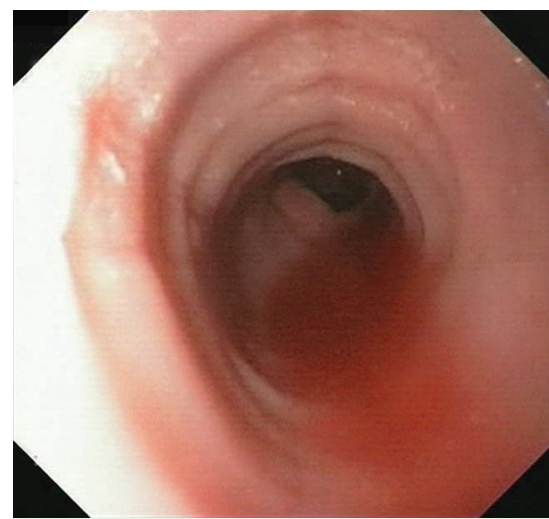

Fig. 2 Endoscopy demonstrated multiple concentric rings along the esophagus ("corrugated esophagus“).

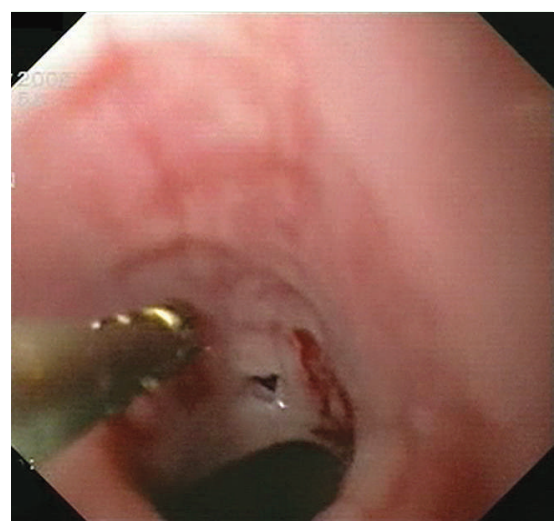

Fig. 3 Endoscopy demonstrated a perforation orifice in the distal esophagus during the biopsy procedure.

A 28-year-old man was admitted to our hospital due to intermittent dysphagia and repetitive episodes of food impaction. No relevant previous clinical history was referred. Physical examination was within normal limits.

Gastroscopy was performed and showed several ulcers in the distal esophagus. The procedure was poorly tolerated and the patient suffered a Mallory-Weiss tear, which required endoscopic sclerosis. Immediately after endoscopy, the patient complained of chest pain. A computed tomography thoracic scan revealed a perforation ( $\bullet$ Fig. $\mathbf{1}$ ), which was managed conservatively with satisfactory clinical outcome.

After 3 months of lansoprazole treatment, a second gastroscopy was indicated due to persistent dysphagia. Endoscopy demonstrated a corrugated esophagus ( $\bullet$ Fig. 2) and the presence of a supracardial fragile mucosa with erosions.

During the biopsy procedure a perforation orifice could be seen ( $\odot$ Fig. 3).

The patient was hospitalized and did well under conservative treatment.

Pathological examination showed a massive eosinophilic infiltration of the esophageal mucosa consistent with the diagnosis of eosinophilic esophagitis ( $\bullet$ Fig. 4). Allergologic studies were positive for dog and cat epithelium. Treatment with topical budesonide and exposure avoidance

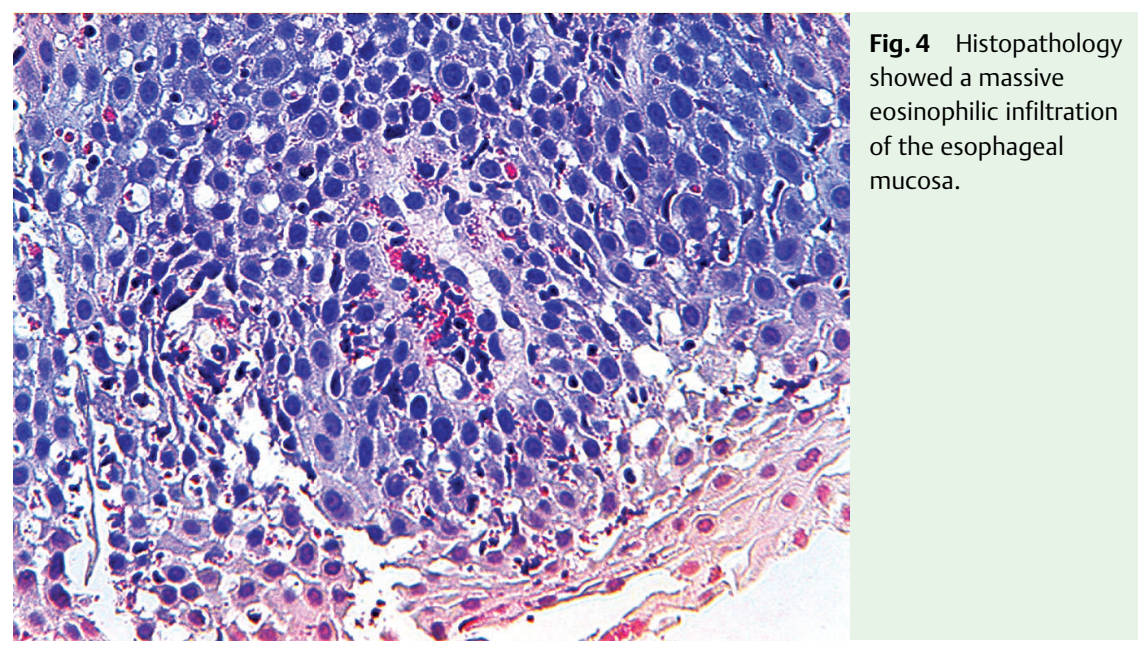

were indicated. After follow-up of 1 year, the patient remains asymptomatic.

Eosinophilic esophagitis is a chronic disease characterized by an eosinophilic infiltration of the esophageal mucosa (> 15 eosinophils/high-power field), the diagnosis of which has increased during the past few years. The predominant symptoms are dysphagia and food bolus impaction episodes in adults, and its main complication is esophageal lumen stenosis [1].

Increasing evidence supports the relevance of an inflammatory process of immunoallergic etiology in eosinophilic esophagitis pathogenesis [2]. Inflamma- tion causes structural changes that lead to a fragile esophageal wall, which increases the perforation risk in the context of diagnostic and therapeutic procedures [3-5].

Therefore, eosinophilic esophagitis must be included in the differential diagnosis of dysphagia. As biopsy samples are essential for diagnosis, special care has to be taken when obtaining these samples, in order to minimize the risk of severe complications such as esophageal perforation.

Endoscopy_UCTN_Code_CPL_1AH_2AB

Endoscopy_UCTN_Code_CPL_1AH_2AF 
Ó. Nantes, F. J. Jiménez, J. M. Zozaya,

\section{J. J. Vila}

Gastroenterology Department, Hospital de Navarra, Pamplona, Spain

\section{References}

1 Furuta GT, Liacouras CA, Collins MH et al. Eosinophilic esophagitis in children and adults: a systematic review and consensus recommendations for diagnosis and treatment. Gastroenterology 2007; 133: $1342-$ 1363

2 Lucendo Villarín AJ, De Rezende L. Eosinophilic esophagitis. Review of current clinical and physiopathological concepts. Gastroenterol Hepatol 2007; 30: 234-243
3 Straumann A, Bussmann C, Zuber $M$ et al. Eosinophilic esophagitis: analysis of food impaction and perforation in 251 adolescent and adult patients. Clin Gastroentero Hepatol 2008; 6: 598-600

4 Robles-Medranda C, Villard F, Bouvier R, Dumortier J, Lachaux A. Spontaneous esophageal perforation in eosinophilic esophagitis in children. Endoscopy 2008; 40 Suppl 2: E171

5 Cohen MS, Kaufman AB, Palazzo JP et al. An audit of endoscopic complications in adult eosinophilic esophagitis. Clin Gastroenterol Hepatol 2007; 5: 1149-1153
Bibliography

DOI $10.1055 / \mathrm{s}-0029-1214693$

Endoscopy 2009; 41: E177-E178

(c) Georg Thieme Verlag KG Stuttgart · New York . ISSN 0013-726X

\section{Corresponding author}

\section{Ó. Nantes, MD}

Gastroenterology Department

Hospital de Navarra

Irunlarrea 3

CP 31008

Pamplona

Spain

Fax: +34-84-8422114

onantes@yahoo.es 